\title{
THE PHYSIOLOGICAL MECHANISM BEHIND THE TALK TEST
}

\author{
Noortje Creemers ${ }^{1}$, Carl Foster ${ }^{1,2}$, John P. Porcari ${ }^{2}$, Maria L. Cress ${ }^{2}$, and Jos J. de Koning ${ }^{1,2}$ \\ ${ }^{1}$ Department of Human Movement Sciences, Faculty of Behavioural and Movement Sciences, \\ Vrije Universiteit Amsterdam, MOVE Research Institute Amsterdam, The Netherlands \\ ${ }^{2}$ University of Wisconsin - La Crosse, Department of Exercise and Sport Science, \\ La Crosse, USA
}

Original scientific paper

UDC: 796.015.86:612

\begin{abstract}
:
The Talk Test (TT) is a very simple marker of exercise intensity, which has been shown to be a useful surrogate of the ventilatory (VT) and respiratory compensation (RCT) thresholds. The purpose of this study was to evaluate a potential mechanism behind the TT. Healthy, college-aged subjects $(n=20)$ performed a maximal and two sub-maximal cycle ergometer tests. The two submaximal tests were performed: with the Talk Test (EXP) and without speaking (the control trial - $\mathrm{CON})$. Oxygen uptake $\left(\mathrm{VO}_{2}\right), \mathrm{CO}_{2}$ output $\left(\mathrm{VCO}_{2}\right)$, minute ventilation $\left(\mathrm{V}_{\mathrm{E}}\right)$, breathing frequency $(\mathrm{BF})$, end-tidal $\mathrm{CO}_{2}$ pressure $\left(P_{\mathrm{ET}} \mathrm{CO}_{2}\right)$ and TT times were recorded. $\mathrm{VO}_{2}, \mathrm{VCO}_{2}$ and $\mathrm{V}_{\mathrm{E}}$ were reduced during the TT and increased immediately after it. BF was reduced during the TT. $P_{\mathrm{ET}} \mathrm{CO}_{2}$ values (a surrogate of $\mathrm{P}_{\mathrm{a}} \mathrm{CO}_{2}$ ) were highest during the TT and lowest before the TT. The time to complete the TT increased across progressive stages. This study supports the hypothesis that talking causes $\mathrm{CO}_{2}$ retention, which may cause ventilatory drive to increase. Since the ventilatory drive is already high above the VT, the apparent $\mathrm{CO}_{2}$ retention associated with speech may cause talking to become uncomfortable.
\end{abstract}

Key words: exercise prescription, exercise test, metabolic thresholds, respiratory gas exchange, speech

\section{Introduction}

Over 35 years ago it became evident that 'the relative percent concept' for exercise prescription had certain deficiencies (Katch, Weltman, Sady, \& Freedson, 1978; Scharhag-Rosenberger, Meyer, Gassler, Faude, \& Kindermann, 2010). Further, when using the relative percent concept as a basis for exercise prescription, a maximal exercise test is required (Pescatello, 2014). In both preventative and rehabilitation populations this is inconvenient or even impossible, meaning that the most strongly evidence-based method of prescribing exercise intensity is, in a practical sense, less than ideally useable. Further, using maximal test derived variables during exercise training is not simple because it usually requires direct monitoring of HR during training sessions.

A recent consensus document has suggested that concepts based on metabolic thresholds are preferable for exercise prescription (Mezzani, et al., 2012). However, this presents the same practical limitation as the relative percent concept, in that direct measurement of metabolic thresholds is costly and technically demanding. Given the prac- tical limitations on evaluation-based methods for exercise prescription, subjective methods of guiding exercise training intensity have become popular. In recent years the Rating of Perceived Exertion (RPE) (Borg, 1998; Eston, 2012) and the Talk Test (TT) have been studied extensively. Both RPE (Parfitt, Evans, \& Eston, 2012) and the TT have been shown to be valid and reliable methods for exercise intensity prescription (Foster, et al., 2008; Woltmann, et al., 2015). The TT, which may present a surrogate of both ventilatory (VT) and respiratory compensation (RCT) thresholds (Dehart-Beverley, Foster, Porcari, Fater, \& Mikat, 2000; Foster, et al., 2008; Recalde, et al., 2002), has the advantage of fitting into a threshold-based scheme of exercise prescription (Mezzani, et al., 2012).

The concept of the TT originated in 1939, when mountaineers were told not to climb at a pace faster than that at which they were able to speak comfortably (Goode, 2008). During incremental exercise the last positive (LP) stage of the TT (the last stage where the subject is definitely able to speak comfortably) is typically observed at intensities just below the VT. The equivocal (EQ) 
stage (the stage when the subject is first uncertain if he/she can speak comfortably) is typically very close to the VT. The first negative (N) stage of the TT (the stage when the subject is first definitely not able to speak comfortably) typically matches the RCT (Dehart-Beverly, et al., 2000; Recalde, et al., 2002; Rodriguez-Marroyo, Villa, Garcia-Lopez, \& Foster, 2013). However, other than the observation that stages of the TT correspond with metabolic thresholds, it is not clear why the TT behaves in such a convenient manner.

Breathing has multiple purposes, the most important being respiratory gas exchange. Breathing is also a necessary step in the production of sound (e.g. speech). Speech requires a decrease in ventilation $\left(\mathrm{V}_{\mathrm{E}}\right)$, particularly because breathing frequency (BF) must be suppressed to allow speaking using continuous, fluent sentences. When speaking, the expiratory duration must be increased since speech is produced only during expiration. The need for longer expiration while speaking during exercise causes a conflict because BF normally increases during exercise, particularly at about the intensity of the ventilatory threshold (Wasserman, et al., 2011).

The physiological mechanism behind the TT is thought to center on the conflict between the need to suppress BF to allow speech and the need to increase BF because of an increased ventilatory drive above the VT (Brawner, et al., 2006). Goode (2008) suggests that epinephrine, norepinephrine and $\mathrm{H}^{+}$all increase beyond the 'anaerobic threshold', leading to an increase in the drive to breathe including an increase in BF. Although the increase in $\mathrm{V}_{\mathrm{E}}$ and $\mathrm{BF}$ at the $\mathrm{VT}$ and RCT is likely driven by neutrally-based feed-forward mechanisms rather than by buffering of blood borne metabolites, the net result is that the mismatch of normal breathing mechanics during speech results in decreases in speech comfort. This change in speech comfort conceivably accounts for the practical utility of the EQ and N stages of the TT as surrogates of VT and RCT, respectively.

The suppression of ventilation, because of a decrease in $\mathrm{BF}$ during speech, can lead to the reduction in both $\mathrm{VO}_{2}$ and $\mathrm{VCO}_{2}$, secondary to a decrease in $\mathrm{V}_{\mathrm{E}}$. While ATP needs can be met briefly using non- $\mathrm{VO}_{2}$ dependent sources, there is virtually no alternative way to deal with reductions in $\mathrm{VCO}_{2}$, except for increasing arterial $\mathrm{CO}_{2}$ partial pressure $\left(P_{\mathrm{a}} \mathrm{CO}_{2}\right)$. However, an increase in $P_{\mathrm{a}} \mathrm{CO}_{2}$ typically causes a dramatic increase in the drive to breathe and the sensation of breathlessness (Wasserman, et al., 2011). Indeed, it is normal for $P_{\mathrm{a}} \mathrm{CO}_{2}$ to decrease above the intensity associated with the $\mathrm{RCT}$, presumably as a strategy to control the drive to breathe in the face of metabolic acidosis. This suggests that the need to suppress total ventilation and breathing frequency to allow speech might lead to an increase in $P_{\mathrm{a}} \mathrm{CO}_{2}$ which would increase the drive to breathe, and be interpreted as a decrease in the comfort of producing speech as a plausible mechanism behind the utilitarian value of the TT. The purpose of this study was to test the hypothesis that an increase in $P_{\mathrm{a}} \mathrm{CO}_{2}$ during speaking explains the decrease in speech comfort.

If speech causes a decrease in $\mathrm{BF}$ and $\mathrm{V}_{\mathrm{E}}$, and a decrease in $\mathrm{VO}_{2}$ and $\mathrm{VCO}_{2}$, we expect an increase in $P_{\mathrm{a}} \mathrm{CO}_{2}$ during speech. However, while $P_{\mathrm{a}} \mathrm{CO}_{2}$ is inconvenient to measure routinely, end-tidal $\mathrm{CO}_{2}$ pressure $\left(P_{\mathrm{ET}} \mathrm{CO}_{2}\right)$ is well accepted as a surrogate of $P_{\mathrm{a}} \mathrm{CO}_{2}$. Respiratory measurement of $P_{\mathrm{ET}} \mathrm{CO}_{2}$ during speech can provide insight into the behavior of $P_{\mathrm{a}} \mathrm{CO}_{2}$. Our hypothesis was that speaking contributes to retention of $\mathrm{CO}_{2}$, which increases $P_{\mathrm{a}} \mathrm{CO}_{2}$ and the ventilatory drive. When the ventilatory drive becomes too high, suppression of BF for speech becomes more difficult and speaking is no longer perceived as comfortable, leading to discrimination between LP, EQ and N TT stages as surrogates of VT and RCT.

\section{Methods}

\section{Participants}

The participants in this study were 20 healthy students. Characteristics of the participants are presented in Table 1. None of the participants were active in competitive sports, although all were recreationally active. Written informed consent was obtained from the participants included in the study, based on the principles articulated in the Declaration of Helsinki. All participants filled out the Physical Activity Readiness Questionnaire (PAR-Q) to rule out contraindications for exercise. The local human subjects committee approved the protocol.

Table 1. Descriptive characteristics of the participants (mean $\pm S D$ )

\begin{tabular}{lcc}
\hline & Men $(\mathrm{n}=8)$ & Women $(\mathrm{n}=11)$ \\
\hline Age (years) & $22.0 \pm 1.9$ & $23.2 \pm 1.2$ \\
Height $(\mathrm{cm})$ & $177.9 \pm 3.8$ & $169.4 \pm 6.8$ \\
Body mass $(\mathrm{kg})$ & $78.9 \pm 10.6$ & $65.5 \pm 9.5$ \\
$\mathrm{VO}_{2} \max \left(\mathrm{ml} \cdot \mathrm{min}^{-1}\right)$ & $2752 \pm 562$ & $2447 \pm 576$ \\
$\mathrm{VO}_{2} \max \left(\mathrm{ml}^{-1} \mathrm{~kg}^{-1} \cdot \mathrm{min}^{-1}\right)$ & $35.2 \pm 7.0$ & $37.5 \pm 7.4$ \\
$\mathrm{VO}_{2} @ \mathrm{VT}\left(\mathrm{ml} / \mathrm{min}^{-1}\right)$ & $1310 \pm 276$ & $1106 \pm 268$ \\
\hline
\end{tabular}

\section{Protocol}

First, the participants performed a graded exercise test on an electronically braked cycle ergometer (Lode Excalibur, Groningen, The Netherlands) to obtain $\mathrm{VO}_{2}$ max. During this test the TT was performed. This test was used for estimating the power output (PO) at different TT stages for the subsequent two tests. After warming up for 3 
min at a $\mathrm{PO}$ of $25 \mathrm{~W}$, the $\mathrm{PO}$ was increased by $25 \mathrm{~W}$ every 3 min until participant's exhaustion. During the last $45 \mathrm{~s}$ of every stage the subject was asked to recite a standard 101-word paragraph (DehartBeverly, et al., 2000) from a cue card. After reciting the passage the subject was asked: "Can you speak comfortably?" The possible answers were 'yes', 'yes, but...' or 'no'. The last stage at which the participant said 'yes' was denoted as the last positive (LP) stage of the TT. The first stage where the subject gave the answer 'yes, but...' was denoted as the equivocal (EQ) stage and the first stage the participant was definitely not able to speak comfortably was denoted as the negative (N) stage. After the $\mathrm{N}$ stage of the TT the subject was not asked to recite the passage, but continued cycling until volitional cessation.

Tests 2 and 3 were performed in a counterbalanced order. The tests started at the PO two stages below the LP stage (LP-2) from the $\mathrm{VO}_{2}$ max test. Every 3 minutes the PO was increased by $25 \mathrm{~W}$ until the PO of the N stage was completed. During the experimental (EXP) test, at 2:15 min into each stage the participant was asked to recite the TT, the same (101-word passage) used during the $\mathrm{VO}_{2} \mathrm{max}$ test. During the control test (CON - test 3$)$ subjects were asked to breathe normally.
During all tests respiratory gas exchange was recorded breath-by-breath using the Oxycon Mobile (CareFusion Corp., San Diego, CA). A facemask was used, so the subjects could speak during the experiments. The respiratory variables recorded were oxygen uptake $\left(\mathrm{VO}_{2}\right)$, carbon dioxide output $\left(\mathrm{VCO}_{2}\right)$, pulmonary ventilation $\left(\mathrm{V}_{\mathrm{E}}\right)$, breathing frequency (BF) and end-tidal $\mathrm{CO}_{2}$ pressure $\left(P_{\mathrm{ET}} \mathrm{CO}_{2}\right)$. During the EXP trial the time required for the 101-word paragraph was measured. $P_{\mathrm{ET}} \mathrm{CO}_{2}$ was taken as a surrogate for pulmonary capillary $P_{a} \mathrm{CO}_{2}$ (Wasserman, et al., 2011). Between the tests there was at least one rest day. The overall activity pattern of the subjects did not change during their participation in the study.

\section{Data analysis}

Before starting the analysis, the data was visually inspected. The patterns of $\mathrm{BF}$ and $P_{\mathrm{ET}} \mathrm{CO}_{2}$ in a trial with TT are shown in Figure 1. The speech passages are easy to recognize by a sharp decrease in $\mathrm{BF}$ and a sharp increase in the $P_{\mathrm{ET}} \mathrm{CO}_{2}$ during the TT. Because this was the case, we selected data guided by the recorded time when the TT was started and ended.

All data was converted from breath-by-breath values to values per second using Matlab (Math-

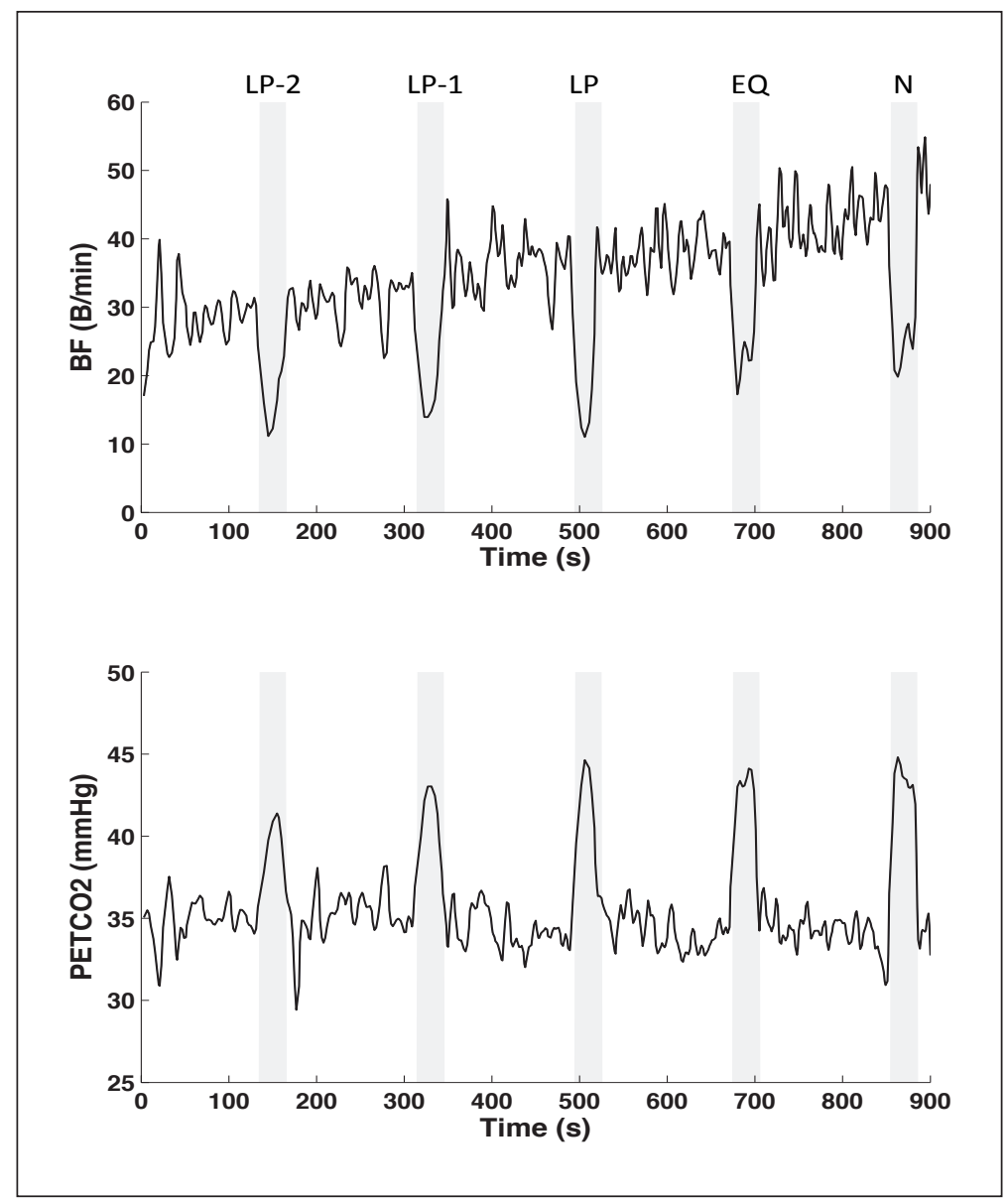

Figure 1. Pattern of BF and PETCO2 during an experimental trial of a representative subject. The recitation of the standard 101-word paragraph of the TT at LP-2, LP-1, LP, EQ and N stage took place at the gray areas. 


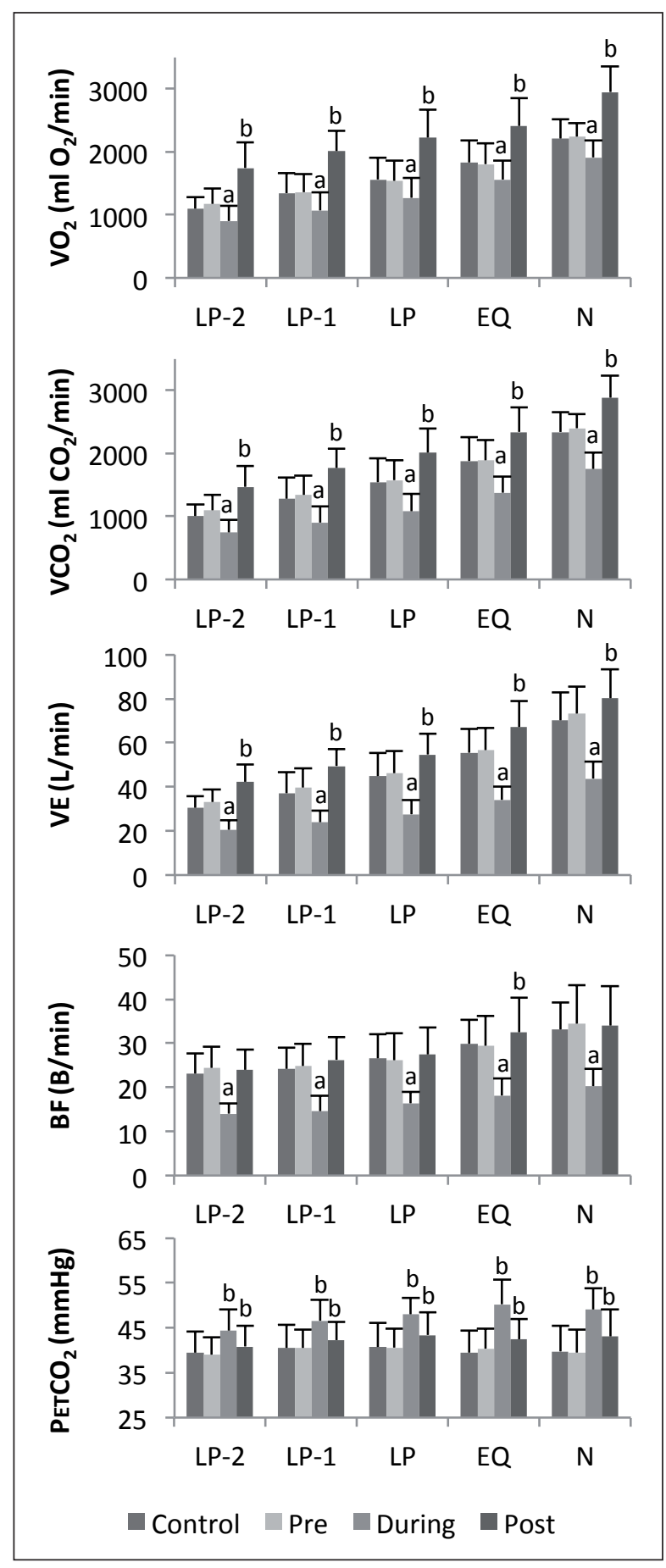

Figure 2. VO2, VCO2, VE, BF and PETCO2 at the LP-2, $L P-1, L P, E Q$ and $N$ stages during the control trial and at pre TT, during TT and post TT during the experimental trial. Statistical significant smaller responses compared to pre TT values are indicated by ' $a$ ' and statistical significant larger responses compared to pre TT values are indicated by ' $b$ '.

works, Matlab R2013a). The last minute of each stage was analyzed. Average values were calculated for the last 15 seconds before the TT, the time during the TT and the first 15 seconds after the TT. Because the timing of the standard 101-word paragraph of the TT was different in each subject and every stage, the averages for the timing of the TT could not always be taken for exactly 15 seconds.
In this case the averages of the available number of seconds within that minute were taken. Also, for the $\mathrm{CON}$ trial the averages of the last minute in each stage were calculated.

For each variable, differences between measurements (Control, Pre, During, Post) at each stage of the TT (LP-2, LP-1, LP, EQ, N) were compared using repeated measures analysis of variance (ANOVA). When justified by the ANOVA results, the differences between specific means were identified using Tukey's post-hoc procedures. Data were analyzed using SPSS (ver. 22) and a significance level of $\mathrm{p} \leq .05$ was used for all analyses.

\section{Results}

$\mathrm{VO}_{2}, \mathrm{VCO}_{2}, \mathrm{~V}_{\mathrm{E}}, \mathrm{BF}$ and $P_{\mathrm{ET}} \mathrm{CO}_{2}$ values for the CON trial and pre TT, during TT and post TT during the EXP trial for the LP-2, LP-1, LP, $E Q$, and $N$ stages are presented in Figure 2. The values pre TT were not significantly different from $\mathrm{CON}$ values. $\mathrm{VO}_{2}, \mathrm{VCO}_{2}$ and $\mathrm{V}_{\mathrm{E}}$ were significantly decreased during speech and significantly increased immediately after the speech compared to pre TT, which is in line with the hypothesized result. BF was significantly decreased during speech, supporting the hypothesis that speaking causes a reduction in BF. This also shows that disruption of ventilation and respiratory gas exchange occurred only during the TT itself. Due to the reduced $\mathrm{BF}$ and $\mathrm{V}_{\mathrm{E}}$ during speech, $P_{\mathrm{ET}} \mathrm{CO}_{2}$ of the limited breaths during speech was significantly increased. $P_{\mathrm{ET}} \mathrm{CO}_{2}$ post TT returned toward normal, but was still significantly higher than the pre TT. Together with the decrease in $\mathrm{VCO}_{2}$ during TT, these results support the hypothesis that speaking causes retention of $\mathrm{CO}_{2}$ and likely a higher arterial $\mathrm{CO}_{2}$.

The TT times for the LP-2, LP-1, LP, EQ, and N stages were $25.3 \mathrm{~s}(3.6), 25.6 \mathrm{~s}$ (3.7), $26.4 \mathrm{~s}$ (3.5), $27.4 \mathrm{~s}$ (4.9) and $27.7 \mathrm{~s}(5.8)$, respectively, showing a nonsignificant increase in the time required to complete reciting the standard paragraph across stages.

\section{Discussion and conclusions}

The TT is a very simple and useful marker of exercise intensity, and has been shown to be closely related to the VT and RCT (Dehart-Beverly, et al., 2000; Recalde, et al., 2002; Rodriguez-Marroyo, et al., 2013), and to be both useful and user-friendly for prescribing exercise in people ranging from cardiac patients to elite athletes (Brawner, et al., 2006; Foster, et al., 2009; Petersen, Maribo, Hjortdal, \& Lausten, 2014; Rodriguez-Marroyo, et al., 2013; Voelker, et al., 2001; Zanettini, et al., 2013). However, other than a known suppression of BF during speech, there has been little direct evidence of why the TT works so effectively.

The main purpose of this study was to test the hypothesis that the physiological mechanism 
behind the TT was related to suppression of $\mathrm{BF}$, with resulting decreases in $\mathrm{V}_{\mathrm{E}}$ and $\mathrm{VCO}_{2}$, leading to an increase in $P_{\mathrm{ET}} \mathrm{CO}_{2}$. The presented results are in accordance with earlier research showing a decrease in $\mathrm{V}_{\mathrm{E}}$ and an increase in $P_{\mathrm{ET}} \mathrm{CO}_{2}$ during speech (Doust \& Patrick, 1981; Meckel, Rotstein, $\&$ Inbar, 2002). The results of our study support the concept that the decrease in $\mathrm{VCO}_{2}$ observed during speaking leads to an increase in $P_{\mathrm{a}} \mathrm{CO}_{2}$ and thus to an increase in the drive to breathe, which consequently influences speech comfort. In accordance with our expectations, it was found that $\mathrm{VO}_{2}, \mathrm{VCO}_{2}$, $\mathrm{V}_{\mathrm{E}}$, and $\mathrm{BF}$ were decreased during speech, but that $P_{\mathrm{ET}} \mathrm{CO}_{2}$ increased in a manner consistent with the idea of $\mathrm{CO}_{2}$ retention during speech.

$P_{\mathrm{ET}} \mathrm{CO}_{2}$ of the limited number of breaths taken during speaking were increased. $P_{\mathrm{ET}} \mathrm{CO}_{2}$ values are thought to be a reasonable surrogate for $P_{\mathrm{a}} \mathrm{CO}_{2}$ values (Wasserman, et al., 2011). Our results show lower $\mathrm{VCO}_{2}$ and higher $P_{\mathrm{ET}} \mathrm{CO}_{2}$ during speech, supporting the idea that speaking causes retention of $\mathrm{CO}_{2}$, likely contributing to a higher arterial $\mathrm{CO}_{2}$. This supports the concept that an increase in $P_{\mathrm{a}} \mathrm{CO}_{2}$ is plausibly responsible for the progressive loss in speech comfort. However, since there was not a progressive increase in $P_{\mathrm{ET}} \mathrm{CO}_{2}$ as exercise intensity increased, it seems reasonable to suggest that the increasing BF across stages and the slight increase in speech duration while completing the 101-word passage served to limit the magnitude of increase in $P_{\mathrm{ET}} \mathrm{CO}_{2}$ (i.e. $P_{\mathrm{a}} \mathrm{CO}_{2}$ ), with a loss in speech comfort as the result. In the present study, we did not observe the decrease in $P_{\mathrm{ET}} \mathrm{CO}_{2}$ that often occurs during exercise at intensities above the RCT. However, as the N stage of the TT is thought to occur at approximately the RCT, we likely stopped the test before the normal decrease in $P_{\mathrm{ET}} \mathrm{CO}_{2}$ had a chance to occur.

During speech $P_{\mathrm{ET}} \mathrm{CO}_{2}$ was shown to be significantly higher than before speaking. Since $P_{\mathrm{ET}} \mathrm{CO}_{2}$ is thought to be a surrogate measure of $P_{\mathrm{a}} \mathrm{CO}_{2}$, the data suggest that $\mathrm{CO}_{2}$ was retained during speech. This study supports the hypothesis that talking causes $\mathrm{CO}_{2}$ retention which causes the ventilatory drive to increase. Above the VT the ventilatory drive is already high and the increase in $P_{\mathrm{a}} \mathrm{CO}_{2}$ causes speech to become uncomfortable. This appears to be a reasonable candidate for the mechanism behind the Talk Test.

\section{References}

Borg, G. (1998). Borg's perceived exertion and pain scales. Champaign, IL: Human Kinetics.

Brawner, C.A., Vanzant, M., Ehrman, J., Foster, C., Porcari, J.P., Kelso, A.J., et al. (2006). Guiding exercise using the Talk Test among patients with coronary artery disease. Journal of Cardiopulmonary Rehabilitation and Prevention, 26, 72-75.

Dehart-Beverly, M., Foster, C., Porcari, J.P., Fater, D.C., \& Mikat, R.P. (2000). Relationship between the Talk Test and ventilatory threshold. Clinical Exercise Physiology, 2, 34-38.

Doust, J., \& Patrick, J. (1981). The limitation of exercise ventilation during speech. Respiratory Physiology, 46, 137-147.

Eston, R. (2012). Use of rating of perceived exertion in sports. International Journal of Sports Physiology and Performance, 7, 175-182.

Foster, C., Porcari, J.P., Battista, R., Udermann, B., Wright, G.A., \& Lucia, A. (2008). The risk in exercise training. American Journal of Lifestyle Medicine, 2, 279-284.

Foster, C., Porcari, J.P., Gibson, M., Wright, G.A., Greany, J., Talati, N., et al. (2009). Translation of submaximal exercise test responses to exercise prescription using the Talk Test. Journal of Strength and Conditioning Research, 23, 2425-2429.

Goode, R. (2008). A personal insight into the origin of the "Talk Test". Journal of Canadian Society of Sports Medicine, $1,5-8$.

Katch, V., Weltman, A., Sady, S., \& Freedson, P. (1978). Validity of relative percent concept for equating training intensity. European Journal of Applied Physiology, 39, 219-227.

Meckel, Y., Rotstein, A., \& Inbar, O. (2002). The effects of speech production on physiological responses during submaximal exercise. Medicine and Science in Sports and Exercise, 34, 1337-1343.

Mezzani, A., Hamm, L., Jones, A., McBride, P., Moholdt, T., Stone, J., et al. (2012). Aerobic exercise intensity assessment and prescription in cardiac rehabilitation: A joint position statement of the European Association of Cardiovascular Prevention and Rehabilitation, the American Association of Cardiovascular and Pulmonary Rehabilitation and the Canadian Association of Cardiac Rehabilitation. Journal of Cardiopulmonary Rehabilitation and Prevention, $32,327-350$.

Parfitt, G., Evans, H., \& Eston, R. (2012). Perceptually regulated training at RPE13 is pleasant and improves physical health. Medicine and Science in Sports and Exercise, 44, 1613-1618.

Pescatello, L.S. (2014). ACSM's Guidelines for Exercise Testing and Prescription (9 ${ }^{\text {th }}$ ed.). Baltimore, MD: Lippincott Williams \& Wilkins. 
Petersen, A.K., Maribo, T., Hjortdal, V.E., \& Lausten, S. (2014). Intertester reliability of the Talk Test in a cardiac population. Journal of Cardiopulmonary Rehabilitation and Prevention, 34, 49-54.

Recalde, P., Foster, C., Skemp-Arlt, K., Fater, D., Neese, C., \& Dodge, C. (2002). The Talk Test as a simple marker of ventilatory threshold. South African Journal of Sports Medicine, 8, 5-8.

Rodriguez-Marroyo, J., Villa, J., Garcia-Lopez, J., \& Foster, C. (2013). Relationship between the Talk Test and ventilatory thresholds in well-trained cyclists. Journal of Strength and Conditioning Research, 27, 1942-1949.

Scharhag-Rosenberger, F., Meyer, T., Gassler, N., Faude, O., \& Kindermann, W. (2010). Exercise at given percentages of $\mathrm{VO}_{2}$ max: Heterogeneous metabolic responses between individuals. Journal of Science and Medicine in Sport, 13, 74-79.

Voelker, S., Foster, C., Porcari, J.P., Skemp-Arlt, K., Brice, G., \& Backes, R. (2001). Relationship between the Talk Test and ventilatory threshold in cardiac patients. Clinical Exercise Physiology, 4, 120-123.

Wasserman, K., Hansen, J., Sue, D., Stringer, W., Sietsema, K., Sun, X., et al. (2011). Principles of exercise testing and interpretation: Including pathophysiology and clinical applications. Philadelphia, PA: Lippincott Williams \& Wilkins.

Woltmann, M.L., Foster, C., Porcari, J.P., Camic, C.L., Dodge, C., Haible, S., et al. (2015). Evidence that the Talk Test can be used to regulate exercise intensity. Journal of Strength and Conditioning Research, 29, 1248-1254.

Zanettini, R., Centeleghe, P., Franzelli, C., Mori, I., Benna, S., Penati, C., et al. (2013). Validity of the Talk Test for exercise prescription after myocardial revascularization. European Journal of Preventive Cardiology, 20 , 376-382.

Submitted: January 12, 2017

Accepted: March 6, 2017

Correspondence to:

Carl Foster, Ph.D., FACSM

Department of Exercise and Sport Science

University of Wisconsin-La Crosse

La Crosse, WI 54601, USA

Phone: 6087858687

E-mail: cfoster@uwlax.edu

\section{Acknowledgements}

Many thanks to Christopher Dodge and Timo Lesterhuis for their technical assistance during data collection and analysis.

\section{Conflict of Interest}

The authors declare that they have no conflict of interest. 